\title{
Influence of different manipulation methods on the microhardness of nanoparticulate restorative composites
}

\begin{abstract}
The aim of this study was to evaluate the influence of different manipulation techniques on the microhardness of two nanoparticulate restorative composites. Sixty-six specimens were prepared, which were distributed into 8 groups according to the restorative material (Filtek Z350 XT ${ }^{\circledR}$ and Evolu- $\mathrm{X}^{\circledR}$ ) and manipulation technique: digital manipulation; digital manipulation and rubbing of gloves with $70 \%$ alcohol; glass plate manipulation; glass plate manipulation previously rubbed with $70 \%$ alcohol. Resin increments were inserted into a bipartite Teflon matrix with orifice $(5 \mathrm{~mm} \times 3 \mathrm{~mm})$ and photopolymerized with $750 \mathrm{~mW}$ $\mathrm{cm}^{2}$ laser apparatus for 40 seconds and stored in deionized water at $37^{\circ} \mathrm{C}$ for 24 hours. Specimens were then included in polyvinyl chloride rings for subsequent surface planing and microhardness testing (Vickers penetrator, $50 \mathrm{~g} / 15 \mathrm{~s}$ ). Data were submitted to descriptive and inferential statistical analysis (significance level of 5\%). In groups where Filtek Z350 $\mathrm{XT}^{\circledR}$ resin was used, hardness variation from $30 \mathrm{HV}$ to $89.00 \mathrm{HV}$ was observed, while for Evolu- $\mathrm{X}^{\circledast}$ resin, the lowest averages were obtained in groups whose manipulation was digital with $(59.27 \mathrm{HV})$ and without $(58.85 \mathrm{HV})$ use of $70 \%$ alcohol. Nanoparticulate composites, manipulated by different techniques, did not present a similar mechanical behavior when evaluated by the microhardness test. The highest hardness values were obtained for Filtek $\mathrm{Z} 350 \mathrm{XT}^{\circledR}$ resin, manipulated in glove previously rubbed with $70 \%$ alcohol.
\end{abstract}

Keywords: composite resins, nanocomposites, hardness tests
Volume 8 Issue 7 - 2017

\author{
Alidianne F bia Cabral Xavier,' Olimpia \\ Crispim da Silveira,' Francisco Jo lison \\ Jacobino da Silva, ${ }^{2}$ Waldenia Pereira Freire, \\ Catarina Ribeiro Barros de Alencar,' \\ Alessandro Leite Cavalcanti' \\ 'Departmnet of Dentistry, State University of Paraiba, Brazil \\ ${ }^{2}$ Dental Surgeon, Brazil
}

Correspondence: Alessandro Leite Cavalcanti, Department of Dentistry, State University of Paraiba, Rua das Baraunas, S/NBodocongó, Campina Grande, PB, 58429-500, Brazil, Email dralessandro@ibest.com.br

Received: August 29, 2017| Published: December 18, 2017

\section{Introduction}

Composite resins, initially developed as an alternative to silicate cement and acrylic resin, ${ }^{1}$ have better physical, mechanical and aesthetic properties and may be indicated in the resolution of various clinical situations. ${ }^{2}$ Basically, the structural components of a resinous composite are represented by an organic matrix, filler particles with inorganic load, silane (bonding agent), polymerization initiators / accelerators and a pigmenting agent. ${ }^{3}$ Opacifying agents and some other particles are also present, for example, titanium dioxide. Nanoparticulate composite resins have loads ranging in size from $5 \mathrm{~nm}$ to $100 \mathrm{~nm}$ and are used in the preparation of restorations on anterior and posterior teeth due to their excellent esthetics, surface smoothness and mechanical properties, such as surface hardness. ${ }^{4,5}$ These materials have aesthetic and mechanical properties, being a composite resin of universal use. ${ }^{5,6}$ Although the technique of direct insertion of this restorative material into the dental cavities is the most common, some professionals use the digital manipulation method for being more easy to be inserted into the dental cavity, ${ }^{7}$ which may interfere with the surface hardness values of the material, ${ }^{8,9}$ affecting the clinical longevity of the restoration. ${ }^{10}$ Thus, the aim of the present study was to evaluate the influence of different manipulation techniques on the microhardness of two nanoparticulate restorative composites. It was hypothesized that the different forms of manipulation (digital and glass plate, with or without alcohol use) alter the surface hardness of composites.

\section{Material and methods}

Two restorative composites were used for this study:

1. Filtek Z350XT ${ }^{\circledR}$ (Organic matrix: Bis-GMA, UDMA, BisEMA 6, and small quantities of TEGDMA; Inorganic particle: Non-agglomerated nanoparticles of silica $20 \mathrm{~nm}$ in size and nanoagglomerates formed of zirconium/silica particles ranging from 0.6 to $1.4 \mu \mathrm{m}$ in size Nanofilled; $3 \mathrm{M}$ ESPE, St. Paul, MN, USA).

2. Evolu- $X^{\circledR}$ (Organic matrix: Bis-GMA, Bis-EMA dimethacrylate, Inorganic part: Barium aluminum borosilicate glass silanized, barium borosilicate glass silanized fluoro aluminum, silica nanoparticles Nanohybrid; Dentsply/Caulk, Milford, DE, USA).

\section{Preparation of specimens and definition of groups}

To obtain specimens, a bipartite Teflon matrix was used, with an orifice, which inner surface was polished to avoid adhesion of the material. Sixty-six specimens were prepared, which were distributed into 8 groups according to the restorative material and the manipulation technique (Table 1). After insertion into the matrix, each specimen was photopolymerized with a laser device (XL Curing 3000, 3M Dental Products), with light intensity of $750 \mathrm{~mW} / \mathrm{cm}^{2}$, for 40 seconds. Then, the specimen was removed from the matrix and inverted for photopolymerization of the other surface for the same time period. ${ }^{8}$ At the end of the polymerization stage, specimens were 
stored in the oven in deionized water at $37^{\circ} \mathrm{C}$ for 24 hours in lightproof containers, duly identified according to the group to which the specimen belonged. ${ }^{8}$ Specimens were prepared by including in polyvinyl chloride rings $(2 \mathrm{~cm} \times 1.5 \mathrm{~cm})$, followed by filling with Vipi Flash self-curing acrylic resin (Vipi Ind. Com. Prod. Odontol. Ltda., Pirassununga, SP, Brazil). After polymerization, surface planing was performed with abrasive sandpaper (320 to 1200 grain size) (Extec Cor., Enfield, CT, USA) adapted to a rotating metallographic polishing machine (APL 4, Arotec Ind. Com., Cotia, SP, Brazil) and then polished with $1 \mu \mathrm{m}, 0.3 \mu \mathrm{m}$ and $0.05 \mu \mathrm{m}$ alumina abrasive paste for subsequent microhardness testing. ${ }^{2-11}$

Table I

\begin{tabular}{|c|c|c|}
\hline Group & Restorative Material & Manipulation Technique \\
\hline G I & Filtek Z350 XT® & $\begin{array}{l}\text { Digital manipulation }+ \text { insertion using } \\
\text { spatula }\end{array}$ \\
\hline G II & Filtek Z350 XT® & $\begin{array}{l}\text { Digital manipulation with previous } \\
\text { rubbing gloves with } 70 \% \text { alcohol }\end{array}$ \\
\hline G III & Filtek Z350 XT® & Resin manipulation in glass plate \\
\hline G IV & Filtek Z350 XT® & $\begin{array}{l}\text { Resin manipulation in glass plate } \\
\text { previously rubbed with } 70 \% \text { alcohol }\end{array}$ \\
\hline GV & Evolu-X®, & $\begin{array}{l}\text { Digital manipulation }+ \text { insertion using } \\
\text { spatula }\end{array}$ \\
\hline GVI & Evolu-X®, & $\begin{array}{l}\text { Digital manipulation with previous } \\
\text { rubbing gloves with } 70 \% \text { alcohol }\end{array}$ \\
\hline GVII & Evolu-X®, & Resin manipulation in glass plate \\
\hline G VIII & Evolu-X®, & $\begin{array}{l}\text { Resin manipulation in glass plate } \\
\text { previously rubbed with } 70 \% \text { alcohol }\end{array}$ \\
\hline
\end{tabular}

\section{Michohardness evaluation}

Michohardness Tester FM-700 (Future-Tech Corp., Fujisaki, Kawasaki-ku, Japan) was used with Vickers type diamond penetrator programmed to apply a static load of $50 \mathrm{gf}$ in a time of 15 seconds. Four indentations were made on each specimen. Tests were carried out at controlled temperature and by the same operator.

\section{Data analysis}

Data were submitted to descriptive statistical and inferential analysis (mean and standard deviation), with significance level of 5\% $(\alpha=0.05)$. The Bartlett Variance Homogeneity test was used and then the ANOVA test was applied in the different groups and the Tukey test was used to perform multiple comparisons. Analyses were performed with ASSISTAT software, version 7.7 beta, 2008 for Windows.

\section{Results}

The Filtek $\mathrm{Z} 350 \mathrm{XT}^{\circledR}$ resin presented hardness variation between 79.30 and 89.00 (Groups I to IV). The lowest averages were obtained for the Evolu- $\mathrm{X}^{\circledR}$ resin in groups whose manipulation was digitally performed (Groups V and VI) (Table 2). Table 3 shows the results of the analysis of variance, indicating that there were significant differences between independent variables of the Filtek $\mathrm{Z350} \mathrm{XT}^{\circledR}$ resin. Statistically significant $5 \%$ probability ( $\mathrm{F}$ critical $<\mathrm{F}$ ). Statistically significant difference $(\mathrm{p}<0.05)$ was observed between GI and G II and between GII and GIII (Table 4). Table 5 expresses the results of the analysis of variance, the $\mathrm{F}$ statistics and the probability, indicating that there were no significant differences between independent variables of the Evolu- $\mathrm{X}^{\circledR}$ resin. When applying the Tukey multiple comparison test, no statistically significant difference was observed between the mean values of groups evaluated with the Evolu- $\mathrm{X}^{\circledR}$ resin (Table 6).

Table 2 Micro hardness values distribution according to groups

\begin{tabular}{lll}
\hline Group & Mean & Std. Deviation \\
\hline G I & 79 & 4.31 \\
G II & 89 & 5.38 \\
G III & $8 I . I$ & 4 \\
G IV & 79.3 & 1.58 \\
G V & 58.85 & 2.01 \\
G VI & 59.27 & 2.13 \\
G VII & 63.17 & 3.51 \\
G VIII & 61.32 & 2.28
\end{tabular}

Table 3 Analysis of variance (ANOVA) of the manipulation variable of the Filtek Z350 XT尺 resin microhardness test

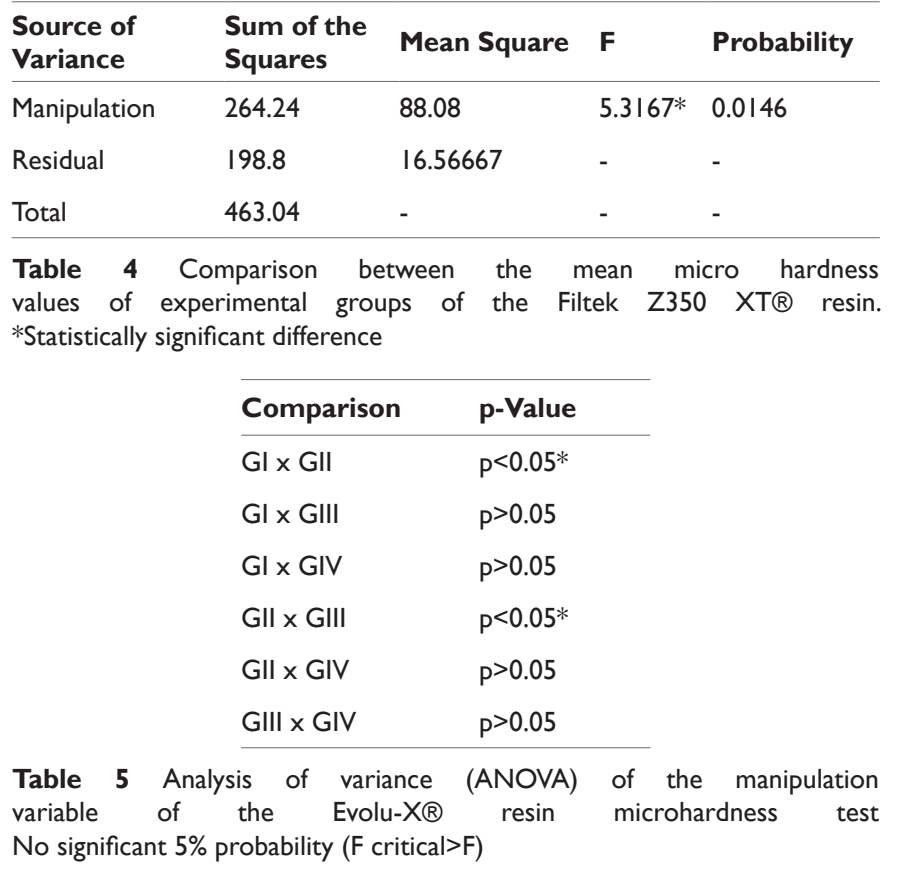

\begin{tabular}{lllll}
\hline $\begin{array}{l}\text { Source of } \\
\text { Variance }\end{array}$ & $\begin{array}{l}\text { Sum of the } \\
\text { Squares }\end{array}$ & Mean Square & F & Probability \\
\hline Manipulation & 58.67188 & 19.55729 & $2.9877^{*}$ & 0.0735 \\
Residual & 78.5525 & 6.54604 & - & - \\
Total & 137.2244 & - & - & - \\
\hline
\end{tabular}

Table 6 Comparison between the mean microhardness values of experimental groups of the Evolu- $X \circledast$ resin

\begin{tabular}{ll}
\hline Comparison & $p$-Value \\
\hline$G V \times$ GVI & $p>0.05$ \\
GV $\times$ GVII & $p>0.05$ \\
GV x GVIII & $p>0.05$ \\
GVI x GVII & $p>0.05$ \\
GVI x GVIII & $p>0.05$ \\
GVII x GVIII & $p>0.05$
\end{tabular}




\section{Discussion}

Evaluating the hardness of resinous composites is crucial to estimate the clinical longevity of these materials, since through this measurement it is possible to estimate the mechanical strength and wear. ${ }^{10}$ The literature indicates that this property can be influenced by factors such as: quantity and size of load particles, ${ }^{12,13}$ light source ${ }^{14}$ and manipulation technique. ${ }^{8,9}$ The present study was conducted to investigate the influence of various manipulation techniques of nanoparticulate composites on the surface microhardness. Among these techniques, digital manipulation has been evaluated, since in some clinical situations, it is observed that prior to insertion of the increment of composite resin into the cavity to be restored, the portion of restorative material removed from the syringe is digitally manipulated in order to facilitate its insertion, placing it in contact with gloves used during the clinical procedure. Considering the obtained results, the established work hypothesis was accepted. In the case of digital manipulation, regardless of resins tested (Filtek Z350 XT ${ }^{\circledR}$ or Evolu- $\mathrm{X}^{\circledR}$ ), manipulation with glove rubbed in $70 \%$ alcohol has achieved higher average hardness values. It should be noted, however, that the Filtek Z350 XT ${ }^{\circledR}$ resin presented the highest microhardness value, showing a statistically significant difference between groups manipulated with glove, with or without alcohol and the group in which manipulation was performed in glove with alcohol and on glass plate without alcohol. Increments manipulated in contaminated gloves and contaminated gloves cleaned with alcohol showed the lowest hardness values. ${ }^{8}$ The manipulation of composite resins can introduce organic and inorganic materials $\mathrm{s}^{15,16}$ and originate porosities, ${ }^{17}$ which can alter its properties. Additionally, cleaning gloves with ethanol can avoid the negative effects of digital manipulation with contaminated gloves, either with the powder present in the glove ${ }^{9-18}$ or with human saliva. ${ }^{9-20}$ In addition, digital manipulation may be important for the resin to achieve better mechanical performance, provided that the gloves are not contaminated. ${ }^{9}$ It should be noted that in the present study, the gloves used did not come into contact with any type of biological material, since the aim was exclusively to investigate the isolated effect of alcohol use on the hardness of nanoparticulate composites. Another factor worth mentioning is the fact that the hardness results should be analyzed with caution, since polymers with similar hardness results may show differences regarding the linearity of the polymer structure and the density of cross links. ${ }^{21,22}$ Nanoparticulate composites have about $84 \%$ of inorganic phase ${ }^{23}$ and higher load content implies a better mechanical behavior. ${ }^{24}$ According to manufacturers' information, Filtek Z350 XT ${ }^{\circledR}$ resin has $78.5 \%$ inorganic load by weight, while Evolu- $\mathrm{X}^{\circledR}$ has a percentage of $75-77 \%$. The justification for the difference found in the hardness values is that the nanometric loads have higher contact surface with the organic phase, improving the hardness of Filtek Z350 XT ${ }^{\circledR}$ resin when compared to Evolu- $\mathrm{X}^{\circledR}$. Among the limitations of this in vitro study, the results showed a great variability in the mechanical behavior of composites tested following the presented protocol. It should be noted that the composite resin does not reach its maximum degree of conversion at the end of the photoactivation, and that the polymerization reaction lasts for up to one week, which leads to an increase in hardness values. Although in the present study, surface hardness was evaluated after 24 hours of photopolymerization, higher hardness values could be found as a function of a longer storage time of specimens. ${ }^{25,26}$

\section{Conclusion}

Nanoparticulate composites, manipulated by different techniques, did not present a similar mechanical behavior when evaluated by the microhardness test. The highest hardness values were obtained for Filtek Z350XT® resin, manipulated in glove previously rubbed with $70 \%$ alcohol.

\section{Funding}

None.

\section{Acknowledgments}

None.

\section{Conflicts of interest}

None.

\section{References}

1. Bowen RL. Properties of a silica- reinforced polimer fordental restorations. Am J Dent. 1963;66:57-62.

2. Debnath S, Ranade R, Wunder S1, Mccool J, Boberick K, et al. Interface effects on mechanical properties of particle-reinforced composites. Dent Mater. 2004;20(7):677-686.

3. Chan KHS, Mai Y, Kim H, Tong KCT, Ng D, et al. Review: Resin composite filling. Materials. 2010;2(3):1228-1243.

4. Moraes RR, Ribeiro DDOS, Klumb MM, et al. In vitro tooth brushing abrasion of dental resin composites: packable, microhybrid, nanohybrid and microfilled materials. Braz Oral Res. 2008;22(2):112-118.

5. Mitra SB, Wu D, Holmes BN. An application of nanotechnology in advanced dental materials. J Am Dent Assoc. 2003;134(10):1382-1390.

6. Rodrigues Junior AS, Zanchi $\mathrm{CH}$, et al. Flexural strength and modulus of elasticity of different types of resin-based composites. Braz Oral Res. 2007;21(1):16-21.

7. Fortkamp S. Influência da manipulação digital com luvas na resistência à compressão e tenacidade à fratura de resinas compostas. Florianópolis: Universidade Federal de Santa Catarina, Brazil, 2007; 157 p.

8. Heck MAP, Kina M, Vieira LCC, et al. Superficial microhardness evaluation of a photopolymerizable composite resin for the use of contaminated gloves during the restorative act. RPG Rev Pós Grad. 2004;17(4):185-190.

9. Martins NM, Schmitt GU, Oliveira HL, et al. Contamination of composite resin by glove powder and saliva contaminants: impact on mechanical properties and incremental layer debonding. Oper Dent. 2015;40(4):396402.

10. Yap AU, Tan SH, Wee SS, et al. Chemical degradation of composite restoratives. J Oral Rehabil. 2001;28(11):1015-1021.

11. Saad JRC, Alvim HH, Duarte Júnior SLL, et al. Evaluation of microhardness of composite resins in function of color and depth. J Bras Clin Odontol Int. 2004;8(47):405-410.

12. Greener EH, Greener CS, Moser JB. The hardness of composites as a function of temperature. J Oral Rehab. 1984;11(4):335-340.

13. Tjan AHL, Chan CA. The polishability of posterior composites. J Prosthet Dent. 1989;61(2):138-146.

14. Barcellos DC, Batista GR, Araújo MAM, et al. Evaluation of hardness of the silorane-based composite resin cured with different photoactivators and after use of mouthwashes. RPG Rev Pós Grad. 2011;18(4): 253-259.

15. Sanders BJ, Pollock A, Weddell JA, et al. The effect of glove contamination on the bond strength of resin o enamel. J Clin Pediatr Dent. 2004;28(4):339-341.

16. Eiriksson SO, Pereira PN, Swift EJ, et al. Effects of saliva contamination on resin-resin bond strength. Dent Mater. 2004;20(1):37-44. 
17. Sarrett DC. Clinical challenges and the relevance of materials testing for posterior composite restorations. Dent Mater. 2005;21(1): 9-20.

18. Guo HJ, Gao CZ, Lin F, et al. Effects of saliva contamination on bond strength of resin-resin interfaces. Beijing Da Xue Xue Bao. 2017;49(1):96100 .

19. Martins NM, Schmitt GU, Oliveira HL, et al. Contamination of composite resin by glove powder and saliva contaminants: impact on mechanical properties and incremental layer debonding. Oper Dent. 2015;40(4):396402.

20. Furuse AY, da Cunha LF, Benetti AR, et al. Bond strength of resin-resin interfaces contaminated with saliva and submitted to different surface treatments. J Appl Oral Sci. 2007;15(6):501-505.

21. Soh MS, Yap AU. Influence of curing modes on crosslink density in polymer structures. J Dent. 2004;32(4):321-326.
22. Asmussen E, Peutzfeldt. A Influence of selected components on crosslink density in polymer structures. Eur J Oral Sci. 2001;109(4): 282-285.

23. Beun S, Glorieux T, Devaux J, et al. Characterization of nanofilled compared to universal and microfilled composites. Dent Mater. 2007;23(1):51-59.

24. Taylor DF, Kalachandra S, Sankarapandian M, et al. Relationship between filler and matrix resin characteristics and the properties of uncured composite pastes. Biomaterials. 1988;19(1-3):197-204.

25. Fraunhofer JAV. The surface hardness of polymeric restorative materials. Br Dent J. 1971;130(16):243-245.

26. Watts DC, Mcnaughton V, Grant AA. The development of surface hardness in visible light-cured posterior composites. J Dent. 1986;14(4):169-174. 